\title{
Adsorption of indigo carmine and methylene blue dye: Taguchi's design of experiment to optimize removal efficiency
}

\author{
TRIPTI B GUPTA ${ }^{1}$ and DILIP H LATAYE ${ }^{2, *}$ \\ ${ }^{1}$ Department of Civil Engineering, Ramdeobaba College of Engineering and Management, Nagpur 440013, \\ India \\ ${ }^{2}$ Department of Civil Engineering, Visvesvaraya National Institute of Technology, Nagpur 440010, India \\ e-mail: dhlataye@civ.vnit.ac.in; diliplataye@ rediffmail.com
}

MS received 13 September 2017; revised 18 April 2018; accepted 19 April 2018; published online 3 September 2018

\begin{abstract}
In the present study, Taguchi's experimental methodology has been applied to find optimum level (value) of adsorption parameters (factors) for the removal of indigo carmine dye (ICD) and methylene blue dye (MBD) using activated carbon derived from Acacia Nilotica sawdust (ACSA). The effect of significant adsorption parameters, viz. adsorbent dose $(m)$, initial concentration $\left(C_{0}\right)$, temperature $(T)$ and contact time $(t)$, on the adsorption capacity $\left(q_{t}\right)$ of ACSA for each dye has been discussed. Average values and S/N ratio for each parameter at three different levels have been estimated using $\mathrm{L}_{9}$ orthogonal array (OA). Analysis of variance (ANOVA) has been used to identify the significant parameters and the most favourable optimal conditions for both raw data and S/N data. The study revealed that, for ICD, initial dye concentration is found to be the most significant parameter with $55.8 \%$ contribution followed by ACSA dose, temperature and contact time with $35.7 \%, 5 \%$ and $3.4 \%$ contribution, respectively. For MBD, the ACSA dose $(m)$ is found to be the most significant parameter with $46.4 \%$ contribution followed by initial dye concentration, temperature and contact time with $44 \%, 5.3 \%$ and $4.4 \%$ contribution, respectively. The contact time $(t)$ is found to be the least significant parameter in the overall sorption process for both ICD and MBD. The optimized levels of parameters for both dyes are found to be $A_{1}, B_{3}, C_{3}$ and $D_{3}$. The predicted and average confirmatory values of total dye adsorbed $\left(q_{t}\right)$ on ACSA at optimized levels were found to be 31.02 and $31.01 \mathrm{mg} / \mathrm{g}$, respectively, for ICD and 57.35 and $57.36 \mathrm{mg} / \mathrm{g}$, respectively, for MBD. The percentage removal of ICD and MBD at optimized levels was found to be $77.5 \%$ and $95.4 \%$, respectively.
\end{abstract}

Keywords. Indigo carmine dye; methylene blue dye; adsorption; Taguchi; ANOVA; signal to noise ratio.

\section{Introduction}

Industrial and manufacturing sectors, like paper and plastic, textile, pharmaceutical, leather, carpet, food, cosmetics and printing press, use dye to colour their products and also consume a huge volume of water. As an outcome, they discharge a massive quantity of dye-bearing wastewater into the aquatic systems. There is a need to treat this dyebearing wastewater because its discharge in aquatic systems may harm the aquatic life and also it cannot be used as a resource of water without treatment. A number of treatment methods are used to remove different classes of contaminants from water, especially those that are not easily decomposable. Among different contaminants present in the environment, dyes represent one of the most problematic groups of the contaminant. Due to their intractable nature, direct discharges of dyes into water bodies are considered as a major source of water pollution. This gives

*For correspondence undesirable colour to the receiving water bodies. It also reduces penetration of sunlight to marine biota and combats the biological and photochemical degradation of organic matter [1]. Presently, a number of different biological, physical and chemical methods are widely used for the removal of dyes from wastewater. A few of these methods like chemical oxidation and biodegradation are economical, but the efficiency is low and treatment time required for these methods is more. The methods like advanced oxidation, membrane filtration, electrochemical oxidation and photo-catalytic degradation are efficient to treat wastewater, but the cost of treatment is more. Amongst various methods of treatment, adsorption is an efficient and economical method. The commercial activated carbon (AC) and other adsorbents are preferred for the removal of colour from wastewater. Adsorption technique becomes more effective and more advantageous if the adsorbent used is cost-effective. In the conventional batch adsorption studies the optimum values of parameters are obtained by varying one parameter and keeping other parameters constant. This 
conventional method requires more time and energy to obtain the optimum values of adsorption parameters. The time and energy can be saved if the adsorption parameters are optimized using an optimization technique in which the effects of significant parameters are studied simultaneously.

Taguchi's optimization technique is worldwide popular in conducting experiments and planning a strategy for the quality control of products in manufacturing industries [2]. The main significance of Taguchi's design is that it provides an optimal solution of parametric values based on their intra-parametric interaction to accomplish a process [3]. The methodology emphasizes on designing the quality in products and processes [4]. It is extensively used by many researchers in the field of adsorption for optimization of sorption process parameters [5-8], manufacturing production process [9] and optimization for best quality products [10].

In the present research, Taguchi's DOE methodology has been applied to find optimum adsorption process parameters for the removal of indigo carmine dye (ICD) and methylene blue dye (MBD) using AC derived from Acacia Nilotica sawdust (ACSA) as an adsorbent. ICD is a toxic indigoid class of dye. It is extensively used in drugs, cosmetics and food industries. In spite of numerous usages of ICD, it is toxic to human. Its contact with eyes can cause everlasting injury to conjunctiva and cornea. Fatal anaphylactoid reaction to this dye has also been identified, which may be due to either intrinsic serotonergic properties or drug allergy [11]. It causes clastogenic action on bone marrow chromosomes of mice [12] and it is also found to cause acute haemodynamic effects [13]. MBD is a potent cationic, organic dye. It has many uses in the field of chemistry, biology and food industry as a photosensitizer for oxygen generation and as an optical oxygen sensor [14]. It is a good antiseptic and antioxidant. It is used to dye yarn, cotton, fur, silk, fabric, wool, fibres, etc. Mishandling of this dye leads to serious illness such as vomiting, mental disorder, sweating, fast breathing, etc. [15]. Thus the removal of ICD and MBD from wastewater requires extensive consideration. Some adsorbent materials, like raw sugar agricultural by-products [16], rice husk [17], sugarcane bagasse [18], coir pith [19], etc., are found to be effective for removal of dyes from an aqueous medium.

The current study deals with removal of ICD and MBD from individual aqueous solutions using ACSA as an adsorbent. Taguchi's DOE technique has been applied to optimize the significant adsorption parameters. For this purpose, Taguchi's $3^{4}$ orthogonal array (OA) has been used to perform the experiments. Signal to noise ratio $(\mathrm{S} / \mathrm{N})$ is used to decide the optimal factor. Analysis of variance (ANOVA) has been used to determine the effect of significant parameters and their percentage contribution in the overall process. The effect of various process parameters such as adsorbent dose $(m)$, initial dye concentration $\left(C_{0}\right)$, temperature $(T)$ and contact time $(t)$ on the selected response/quality characteristics has been evaluated for both the dyes separately. To confirm the optimum design at optimum conditions, confirmation experiments were performed.

\section{Materials and methods}

\subsection{Adsorbent preparation}

In the present study, AC derived from sawdust of locally available evergreen babool tree (Acacia Nilotica) has been used as an adsorbent. The sawdust was sieved to obtain uniform size particles in the range of 250-500 $\mu \mathrm{m}$ [20]. In order to eradicate any contaminations or impurities such as ash, filth, dirt, silt, slag, dust, etc., the sawdust was cleaned with doubled distilled water (DDW). First, the cleaned sawdust was dried in the sun for $24 \mathrm{~h}$, and then it was oven dried at $105^{\circ} \mathrm{C}$ for $2 \mathrm{~h}$. Orthophosphoric acid $(50 \mathrm{~mL})$ was mixed with $100 \mathrm{~g}$ of dried sawdust and air dried for $24 \mathrm{~h}$ to produce char. After $24 \mathrm{~h}$, the produced char was activated in a muffle furnace by maintaining the temperature of $400-450^{\circ} \mathrm{C}$ for $1 \mathrm{~h}$. The formed activated carbon (ACSA) was cleaned with DDW thoroughly till the whole acid was removed. Subsequently, it was air dried and afterwards kept in an oven at $105^{\circ} \mathrm{C}$ for $2 \mathrm{~h}$. The same material was used for the adsorption study. The proximate analysis was performed to determine the physical properties of the adsorbent. To study the adsorbent morphology, electron microscopy was performed for pristine and dye-loaded ACSA using a JEOL (Make: JSM 6380-A, JOEL Ltd., Tokyo, Japan) scanning electron microscope at $500 \times$ magnification.

\subsection{Adsorbate preparation}

ICD (chemical formula $\mathrm{C}_{16} \mathrm{H}_{8} \mathrm{~N}_{2} \mathrm{Na}_{2} \mathrm{O}_{8} \mathrm{~S}_{2}$, figure 1a) and MBD (chemical formula $\mathrm{C}_{16} \mathrm{H}_{18} \mathrm{ClN}_{3} \mathrm{~S}$, figure 1b) were procured from M/S Global Marketing, Nagpur, India. Separate standard stock solutions for ICD and MBD of $1000 \mathrm{mg} / \mathrm{L}$ were prepared by dissolving $1 \mathrm{~g}$ of respective dye powder in $1000 \mathrm{~mL}$ DDW. The subsequent concentration solutions were prepared by diluting the respective stock solution of dye as per requirement. The absorbance and wavelength were determined using scanning of the respective solution in a spectrophotometer. The wavelengths corresponding to maximum absorbance for ICD and MBD were found to be 610 and $664 \mathrm{~nm}$, respectively. The samples were analysed using a Shimadzu double-beam UV-VIS spectrophotometer (Model: UV -2450).

\subsection{Taguchi's DOE methodology}

Taguchi's design helps to identify the working levels of the design process parameters. This technique lessens the number of experiments to be carried out based on the 


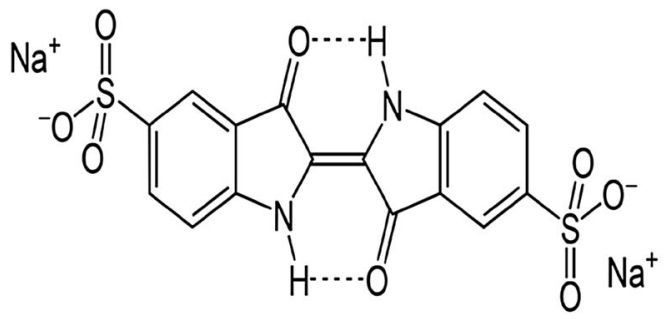

(a)<smiles>CN(C)c1ccc2nc3ccc(=[N+](C)C)cc-3sc2c1</smiles>

(b)

Figure 1. Chemical structure of (a) ICD and (b) MBD.

statistical significance of parameters and the interactive influences of these parameters [3]. It seeks to determine parameter levels that produce the best performance of the process. The OA, ANOVA and $\mathrm{S} / \mathrm{N}$ analysis are the essential tools of parameter design [2].

2.3a Experimental conditions: Taguchi's DOE is an optimization technique. In this methodology, experiments are designed as per OAs for laying out experiments. To design an experiment is to select the most suitable OA and to assign the parameters and interactions of interest to the appropriate columns.

The optimum conditions are identified by analysing the main effects of each of the parameters. There are two different approaches to carry out the complete analysis. In the standard approach, the results of a single run or the average of repetitive runs is accomplished through the main effect and ANOVA (raw data analysis) [3]. In the second approach, multiple runs are taken and the $\mathrm{S} / \mathrm{N}$ for the same steps is used in the analysis.

In the present investigation, both raw data analysis and $\mathrm{S} / \mathrm{N}$ data analysis have been carried out. The effect of selected parameters on the selected quality characteristic has been explored. Total dye adsorbed on the adsorbent $(\mathrm{mg} / \mathrm{g})$ was found through the plots of the main effects based on the raw data. The optimum conditions for the quality characteristic have been established through $\mathrm{S} / \mathrm{N}$ data analysis aided by the raw data analysis. Instead of employing an outer array, experiments have been repeated three times at each experimental condition under batch study.

2.3b Experimental design methodology: Experiments were performed to maximize the total amount of adsorbate adsorbed from the aqueous solutions of ICD and MBD in different combinations in a batch adsorption process. The process parameters, their designations and levels are given in table 1.

2.3c Process parameters: Batch experiments were conducted to study the effect of various process parameters pertaining to adsorption of ICD and MBD from aqueous solutions by ACSA. The parameters like concentration of dyes, amount of adsorbent, contact time and temperature
Table 1. Process parameters for adsorption study of ICD and MBD on ACSA using Taguchi's OA.

\begin{tabular}{|c|c|c|c|c|c|}
\hline \multirow[b]{2}{*}{ Factors } & \multirow[b]{2}{*}{ Parameters } & \multirow[b]{2}{*}{ Units } & \multicolumn{3}{|c|}{ ACSA levels } \\
\hline & & & 1 & 2 & 3 \\
\hline$A$ & ACSA dose $(m)$ & $\mathrm{g} / 50 \mathrm{~mL}$ & 0.25 & 0.50 & 0.75 \\
\hline \multirow[t]{2}{*}{$B$} & ICD concentration $\left(C_{0}\right)$ & $\mathrm{mg} / \mathrm{L}$ & 50 & 100 & 200 \\
\hline & MBD concentration $\left(C_{0}\right)$ & & 100 & 200 & 300 \\
\hline$C$ & $\begin{array}{c}\text { ICD and ACSA } \\
\text { temperature }(T)\end{array}$ & ${ }^{\circ} \mathrm{C}$ & 20 & 30 & 40 \\
\hline \multirow[t]{2}{*}{$D$} & $\begin{array}{c}\text { ICD and ACSA contact } \\
\text { time }(t)\end{array}$ & $\min$ & 90 & 120 & 150 \\
\hline & $\begin{array}{c}\text { MBD and ACSA contact } \\
\text { time }(t)\end{array}$ & & 30 & 60 & 90 \\
\hline
\end{tabular}

influence the efficiency of ACSA in removing ICD and MBD from the aqueous solution.

2.3d Selection of $O A$ and parameter assignment: Before selecting a particular OA for an experiment, (i) the number of parameters and interactions of interest and (ii) the number of levels for the parameters of interest must be established [21]. It depends on the degrees of freedom (DOF). The OA selected must satisfy the following inequality:

total DOF of $\mathrm{OA} \geq$ total $\mathrm{DOF}$ required for the experiment

Normally, ANOVA for OA is conducted in the same manner as other structures experiment [22]. When the ANOVA on the raw data (control parameters that affect the average) and $\mathrm{S} / \mathrm{N}$ data (control parameters that affect the variation) are completed, the control parameters may be put into four classes [21]. Class I: parameters that affect both the average and the variation, Class II: parameters that affect variation only, Class III: parameters that affect average only and Class IV: parameters that affect nothing. Here each selected parameter is analysed at three levels, because non-linear behaviour of the process parameters (if any) can be found only if more than two levels are used [23].

The possible number of experiments $(N)$ is determined using the equation $N=L^{m}$ where $m$ is the number of 
Table 2. Column assignment for various parameters for sorption of ICD and MBD on ACSA.

\begin{tabular}{lccccc}
\hline & & \multicolumn{4}{c}{ Parameters } \\
\cline { 3 - 6 } Order of & & $A$ & $B$ & $C$ & $D$ \\
expt. & Run & $m$ & $C_{0}$ & $T$ & $t$ \\
\hline 6 & 1 & 2 & 3 & 1 & 2 \\
5 & 2 & 2 & 2 & 3 & 1 \\
7 & 3 & 3 & 1 & 3 & 2 \\
2 & 4 & 1 & 2 & 2 & 2 \\
8 & 5 & 3 & 2 & 1 & 3 \\
9 & 6 & 3 & 3 & 2 & 1 \\
3 & 7 & 1 & 3 & 3 & 3 \\
4 & 8 & 2 & 1 & 2 & 3 \\
1 & 9 & 1 & 1 & 1 & 1 \\
\hline
\end{tabular}

parameters and $L$ is number of levels for each parameter. For ACSA, $N=3^{4}$, three levels and four parameters, were chosen. Hence, for full factorial design, number of possible experiments is equal to 81 .

To reduce the number of experiments, only a small possible set was selected. The method of selecting a limited number of experiments that produce most information is known as fractional factorial design [24]. For 81 full factorial designs $\left(3^{4}\right)$, Taguchi used $L_{9}$ OA where 9 indicates number of trial experiments required. With four parameters each at three levels, the total DOF required is $=4(3-1)=8$, since a three-level parameter has two DOF (no. of levels 1). Hence, an $L_{9}\left(3^{4}\right)$ OA (a standard three level OA) has been selected for this work. The $L_{9} \mathrm{OA}$ with an assignment of parameters is shown in table 2 .

As per the selected parameters (factors) in table 1, design of experiment (DOE) was prepared by putting the factor level values in table 2 , and it is presented in table 3 . DOE (as shown in table 3 ) consists of different parameters that

Table 3. Design of experiment (DOE) for sorption of ICD and MBD on ACSA.

\begin{tabular}{|c|c|c|c|c|c|c|c|c|}
\hline \multirow[b]{5}{*}{ Run } & \multicolumn{8}{|c|}{ Parameters } \\
\hline & \multicolumn{2}{|c|}{$A$} & \multicolumn{2}{|c|}{$B$} & \multicolumn{2}{|c|}{$C$} & \multicolumn{2}{|c|}{$D$} \\
\hline & \multicolumn{2}{|c|}{$m$} & \multicolumn{2}{|c|}{$C_{0}$} & \multicolumn{2}{|c|}{$T$} & \multicolumn{2}{|c|}{$t$} \\
\hline & \multicolumn{2}{|c|}{$(\mathrm{g} / 50 \mathrm{~mL})$} & \multicolumn{2}{|c|}{$(\mathrm{mg} / \mathrm{L})$} & \multicolumn{2}{|c|}{$\left({ }^{\circ} \mathrm{C}\right)$} & \multicolumn{2}{|c|}{$(\min )$} \\
\hline & ICD & MBD & ICD & MBD & ICD & MBD & ICD & MBD \\
\hline 1 & 0.5 & 0.5 & 200 & 300 & 20 & 20 & 120 & 60 \\
\hline 2 & 0.5 & 0.5 & 100 & 200 & 40 & 40 & 90 & 30 \\
\hline 3 & 0.75 & 0.75 & 50 & 100 & 40 & 40 & 120 & 60 \\
\hline 4 & 0.25 & 0.25 & 100 & 200 & 30 & 30 & 120 & 60 \\
\hline 5 & 0.75 & 0.75 & 100 & 200 & 20 & 20 & 150 & 90 \\
\hline 6 & 0.75 & 0.75 & 200 & 300 & 30 & 30 & 90 & 30 \\
\hline 7 & 0.25 & 0.25 & 200 & 300 & 40 & 40 & 150 & 90 \\
\hline 8 & 0.5 & 0.5 & 50 & 100 & 30 & 30 & 150 & 90 \\
\hline 9 & 0.25 & 0.25 & 50 & 100 & 20 & 20 & 90 & 30 \\
\hline
\end{tabular}

affect the removal of ICD and MBD significantly. The parameters and ranges were selected based on the batch studies for ICD and MBD removal using ACSA. Based on the experience and batch experiments, four process parameters that have significant influence on the dyes adsorption, viz. adsorbent dose, initial dye concentration, temperature and contact time, were selected for the present study.

2.3e Batch experimental studies: Batch experiments were performed to study the effect of different parameters on adsorption capacity and removal efficiency. These parameters were adsorbent dose, initial dye concentration, $\mathrm{pH}$, contact time and temperature. From the batch study, it was found that optimum ACSA dose and temperature for both ICD and MBD were $0.5 \mathrm{~g} / 50 \mathrm{~mL}$ and $30^{\circ} \mathrm{C}$, respectively. The optimum equilibrium time was found to be 120 and 90 min, respectively, and solution $\mathrm{pH}$ was 6.76 and 6.96, respectively (natural). The significant parameters affecting adsorption process, viz. initial dye concentration, adsorbent dose, contact time and temperature (shown in table 1) were considered for optimization study. In $3^{4} \mathrm{OA}, 4$ parameters at 3 levels were considered as per Taguchi's design of experiment methodology. Three levels (values) of each parameter were taken by considering the optimum value of each parameter as the reference value obtained in batch study. The value less than optimum value has been considered as level one and the value more than optimum has been considered as level three with equal intervals [25]. For adsorptive removal of ICD and MBD by ACSA, optimization is done using selected 9 experimental trials [3], in combination with four parameters at three levels as shown in tables 1 and 3. For each experimental run, $50 \mathrm{~mL}$ of aqueous solution of dyes prepared in DDW at natural $\mathrm{pH}$ (6.76 for ICD and 6.96 for MBD) having different ICD and MBD concentrations was taken in $250 \mathrm{~mL}$ stoppered conical flasks. The required dose of ACSA as per DOE run was added in each flask. These flasks were agitated at a constant shaking speed of $150 \mathrm{rpm}$ in an orbital shaking incubator (Remi Instruments, Mumbai) at required temperatures and time. The experiments were performed in triplicate.

Adsorption capacity $q_{t}$ was calculated using Eq. (1):

$$
q_{t}=\frac{\left(C_{0}-C_{e}\right)}{m}
$$

where $C_{0}$ is the initial dye concentration $(\mathrm{mg} / \mathrm{L}), C_{e}$ is the equilibrium dye concentration $(\mathrm{mg} / \mathrm{L}), m$ is the dose of the adsorbent $(\mathrm{g} / \mathrm{L})$ and $q_{t}$ is the amount of adsorbate adsorbed by the adsorbent at equilibrium ( $\mathrm{mg} / \mathrm{g})$.

\subsection{Analysis of experimental data}

The data obtained from experimental work were analysed by $\mathrm{S} / \mathrm{N}$, which is a logarithmic function used to optimize the variance (either minimize or maximize) and method of ANOVA for raw data. 
2.4a $S / N$ : Taguchi created a transform for the loss function that is called the $S / N$ ratio [2], which looks at two characteristics of a distribution. It combines these two distribution characteristics into a single figure or number of merit. The $S / N$ ratio determines the strongest set of functioning conditions. The outer OA is used to force noise variation into the experiment, i.e., the noise is deliberately introduced into the experiment. For exceedingly noisy conditions, it is not generally obligatory to ascertain specific noise factors and to purposely control them during experimentation. It is sufficient to generate repetitions at each experimental condition of the manageable parameters and investigate them using proper $S / N$ ratio [23].

The $S / N$ ratio combines the quality characteristic of the mean level and the variance around this mean into a single metric system [26]. The $S / N$ ratio reduces the variations of uncontrollable factors [24]. There are three conditional types of $S / N$ ratio as follows (Eqs. (2)-(4)).

smaller and better:

$$
\frac{S}{N}=-10 \log \left[\frac{1}{n} \sum_{i=1}^{n} y_{i}^{2}\right]
$$

nominal and better:

$$
\frac{S}{N}=-10 \log \left[\frac{1}{n} \sum_{i=1}^{n} \frac{1}{y_{i}^{2}}\right]
$$

bigger and better:

$$
\frac{S}{N}=10 \log \frac{\mu^{2}}{\sigma^{2}}
$$

where $\mu^{2}$ is square of mean, $\sigma^{2}$ is variance of observations and $y_{i}$ is observation of response variables for ' $n$ ' trials. Bigger and better $S / N$ condition was used to calculate the variance of data in the present study.

2.4b ANOVA: The raw data and $S / N$ data were further analysed by ANOVA. In ANOVA, many parameters such as DOF, sum of squares, variance, variance ratio, percentage contribution, etc. are considered [27]. The purpose of ANOVA is to inspect the parameter considerably affecting the quality characteristic. DOF $(f)$ is equal to the sum of DOF for a controlled factor and DOF for error [27]. The sum of squares $(S)$ is a measure of the deviation of the experimental data from the mean value of the data [28]. Variance $(V)$ measures the distribution of the mean of data. Variance ratio $(F)$ is used to measure the significance of the factor under investigation with respect to the variance of all the factors included in the error term. The probability values $(p)$ have also been calculated to determine the statistical significance of the process. The percentage contribution (\%) of each factor is obtained by dividing the pure sum of squares for that factor by the sum of square of all trial run results and multiplying the result by 100 [28].
ANOVA is applied to the experimental results to find out the percentage contribution of each parameter against a specified confidence level. The contribution of each parameter can be determined by studying ANOVA table for a given analysis. Each column of OA is associated with two DOF $(\mathrm{DOF}=$ number of levels minus one $)$ and can be assigned one factor. The array should satisfy the following condition: the total DOF for OA should always be greater than or equal to the total DOF of experiment. The detailed methodology for the analysis of experimental data is given by other investigators [5-8]. The raw data were used for the result analysis and to calculate the adsorption performance. After determination of optimum condition, the mean of response $(\mu)$ was predicted.

2.4c Prediction of the mean: ANOVA gives the optimized parameters at significance level. Once optimum conditions are determined, the mean of the response $(\mu)$ at the optimum condition is predicted. This mean is estimated only from significant parameters [29]. Suppose $\bar{A}_{2}, \bar{B}_{2}, \overline{C_{2}}$ and $\overline{D_{2}}$ are the second level optimized parameters, then the mean of the response at optimal condition is estimated as follows:

$$
\begin{aligned}
\mu & =\bar{T}+\left(\bar{A}_{2}-\bar{T}\right)+\left(\bar{B}_{2}-\bar{T}\right)+\left(\bar{C}_{2}-\bar{T}\right)+\left(\bar{D}_{2}-\bar{T}\right) \\
& =\bar{A}_{2}+\bar{B}_{2}+\overline{C_{2}}+\bar{D}_{2}-\bar{T}
\end{aligned}
$$

where $\mu$ is the mean of the response at the optimum condition and $\bar{T}$ is the overall mean of the response; $\bar{A}_{2}, \bar{B}_{2}, \bar{C}_{2}$ and $\overline{D_{2}}$ represent average values of response at the second level of parameters $A, B, C$ and $D$, respectively. The estimation of mean of the response $(\mu)$ is only a point estimate based on the average of results obtained from the experiments.

2.4d Confidence interval determination: The optimized results were checked on confidence interval $(C I)$. $C I$ represents the maximum and minimum value of statistical parameter between which the true mean lies. The mean of the response $\mu$ should fall at some stated level of confidence. The $C I$ is of two types, $C I_{P O P}$, which is confidence interval for entire population, and $C I_{C E}$, which is confidence interval for only a sample group or group of experiments at stated conditions [8]. These confidence intervals are defined as follows:

$$
\begin{gathered}
C I_{P O P}=\sqrt{\frac{F_{\alpha}\left(1, f_{e}\right) V_{e}}{n_{e f f}}} \\
C I_{C E}=\sqrt{F_{\alpha}\left(1, f_{e}\right) V_{e}\left[\frac{1}{n_{e f f}}+\frac{1}{R}\right]}
\end{gathered}
$$

where $F_{\alpha}\left(1, f_{e}\right)$ indicates the $F$-ratio at a confidence level of $(1-\alpha)$ against DOF 1 and error DOF $\left(f_{e}\right)$. The value of 
error DOF can be taken from $F$ table. $V_{e}$ indicates error variance from pooled ANOVA. $R$ indicates the sample size for confirmation experiment and efficiency $\left(n_{\text {eff }}\right)$ is defined as follows:

$$
\begin{aligned}
& n_{\text {eff }}= \\
& \frac{N}{1+[\text { Total DOF associated in the estimate of the mean }]}
\end{aligned}
$$

where $N$ is total number of results.

It can be seen from Eqs. (6)-(8) that as $R$ approaches infinity (i.e., the entire population), the value $1 / R$ approaches zero and $C I_{C E}=C I_{P O P}$. As $R$ approaches $1, C I_{C E}$ becomes wider [5-8].

2.4e Experiment for confirmation: Under optimized conditions, the confirmation experiments were performed for different parameters and the average of end results was checked at 5\% confidence interval [8]. If the values between Taguchi's model and confirmation experiments lie in $5 \%$ confidence interval then it can be considered that the optimal parametric values obtained by Taguchi's design of experimental methodology are valid.

\section{Results and discussion}

\subsection{Characterization of adsorbent}

The sieve analysis had been carried out to get the adsorbent in the size range of $250-500 \mu \mathrm{m}$. Proximate analysis and scanning electron microscopy (SEM) were conducted to get the physical characteristics of the adsorbent (ACSA) used in the study. In the proximate analysis, physical properties of ACSA were determined, which showed that ACSA had $17.6 \%$ moisture content, $9.6 \%$ ash content, $17 \%$ volatile matter and $55.8 \%$ fixed carbon content. The maximum percentage of fixed carbon content indicates carbonaceous nature of ACSA [25]. The adsorption is a surface phenomenon and it depends on the adsorbent's surface morphology and porosity. Figure $2 \mathrm{a}, \mathrm{b}$ and $\mathrm{c}$ shows SEM images of pristine ACSA and ACSA loaded with ICD and MBD, respectively, using the JEOL (Make - JSM 6380-A, JOEL Ltd., Tokyo, Japan) scanning electron microscope at $500 \times$ magnification. These figures show the surface morphology and surface porosity of ACSA. From the images of pristine and loaded ACSA (figure 2c), it can be seen that there are a large number of asymmetrical, uneven and porous cavities having pore diameter $10-50 \mu \mathrm{m}$, indicating mesoporous nature of the adsorbent. These mesopores are accountable for the adsorption of ICD and MBD over its surface. These porous cavities are sufficient to allow the molecules of ICD and MBD to penetrate into the cellulosic honeycomb-like lingo structure and interact therein with the different surface and functional groups. Large pores are clearly seen on the periphery of pristine ACSA. This might be due to the thermal and chemical activation of ACSA through activating agents like carbon and orthophosphoric acid $\left(\mathrm{H}_{3} \mathrm{PO}_{4}\right)$. Pore development in $\mathrm{AC}$ char promotes the diffusion of ICD and MBD dye molecules inside the mesopores. SEM analysis of loaded ACSA shows that there is filling of mesopores and deposition of dye molecules on the surface of ACSA loaded with ICD and MBD. The distortion of well-developed ACSA pores by ICD and MBD molecules is the major reason for higher penetration of ICD and MBD.

\subsection{Taguchi's $L_{9}$ OA experimental methodology and results}

Taguchi's design of experimental strategy is applied in the current study to obtain optimum process parameters for the

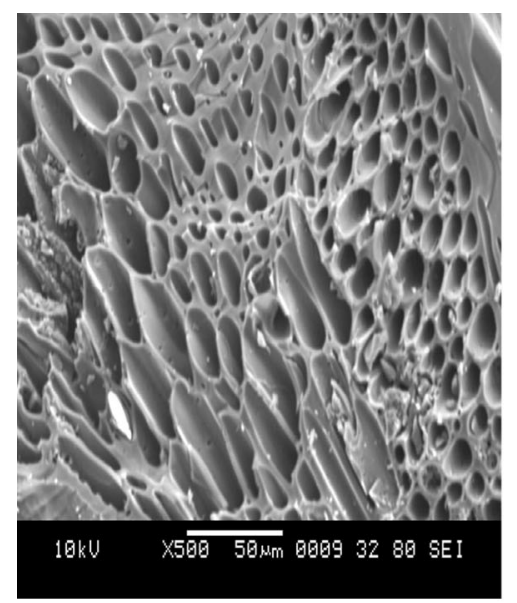

(a)

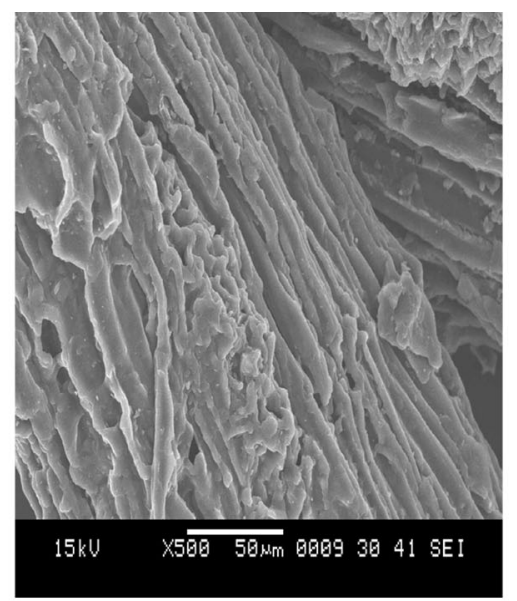

(b)

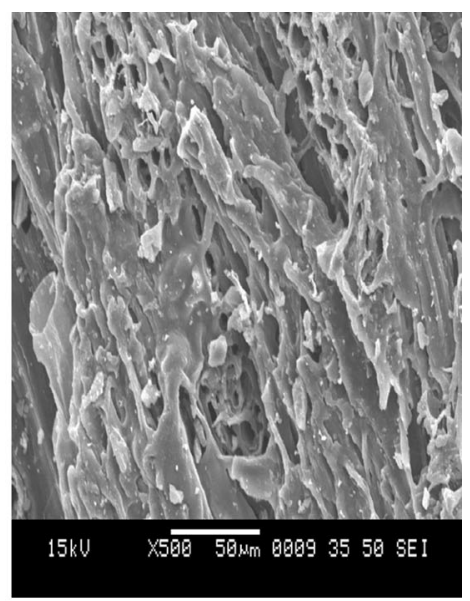

(c)

Figure 2. SEM images of (a) pristine ACSA, (b) ICD-loaded ACSA and (c) MBD-loaded ACSA. 
Table 4. Taguchi's OA with $q_{t}$ values and $S / N$ ratio data for sorption of ICD on ACSA.

\begin{tabular}{|c|c|c|c|c|c|c|c|c|c|c|c|}
\hline \multirow[b]{3}{*}{ Run } & \multicolumn{4}{|c|}{ Parameters } & \multicolumn{6}{|c|}{ Experimental results } & \multirow[b]{3}{*}{$S / N$ ratic } \\
\hline & \multirow{2}{*}{$\frac{A}{m}$} & \multirow{2}{*}{$\frac{B}{C_{0}}$} & \multirow{2}{*}{$\frac{C}{T}$} & \multirow{2}{*}{$\frac{D}{t}$} & \multicolumn{3}{|c|}{$q_{t}(\mathrm{mg} / \mathrm{g})$} & \multicolumn{3}{|c|}{ Percentage removal $(\%)$} & \\
\hline & & & & & $R_{1}$ & $R_{2}$ & $R_{3}$ & $R_{1}$ & $R_{2}$ & $R_{3}$ & \\
\hline 1 & 0.5 & 200 & 20 & 120 & 16.06 & 16.28 & 16.58 & 80.31 & 81.38 & 82.92 & 24.25 \\
\hline 2 & 0.5 & 100 & 40 & 90 & 9.92 & 9.95 & 9.96 & 99.23 & 99.54 & 99.63 & 19.95 \\
\hline 3 & 0.75 & 50 & 40 & 120 & 3.33 & 3.32 & 3.31 & 99.75 & 99.63 & 99.26 & 10.42 \\
\hline 4 & 0.25 & 100 & 30 & 120 & 16.43 & 16.31 & 16.80 & 82.15 & 81.54 & 84.00 & 24.35 \\
\hline 5 & 0.75 & 100 & 20 & 150 & 6.63 & 6.64 & 6.63 & 99.38 & 99.54 & 99.48 & 16.43 \\
\hline 6 & 0.75 & 200 & 30 & 90 & 13.04 & 13.03 & 13.02 & 97.77 & 97.74 & 97.62 & 22.30 \\
\hline 7 & 0.25 & 200 & 40 & 150 & 30.89 & 30.95 & 31.20 & 77.23 & 77.38 & 78.00 & 29.83 \\
\hline 8 & 0.5 & 50 & 30 & 150 & 4.97 & 4.98 & 4.98 & 99.45 & 99.51 & 99.57 & 13.94 \\
\hline 9 & 0.25 & 50 & 20 & 90 & 8.90 & 8.90 & 8.98 & 88.98 & 88.98 & 89.85 & 19.01 \\
\hline
\end{tabular}

Table 5. Taguchi's OA with $q_{t}$ values and $S / N$ ratio data for sorption of MBD on ACSA.

\begin{tabular}{|c|c|c|c|c|c|c|c|c|c|c|c|}
\hline \multirow[b]{3}{*}{ Run } & \multicolumn{4}{|c|}{ Parameters } & \multicolumn{6}{|c|}{ Experimental results } & \multirow[b]{3}{*}{$S / N$ ratic } \\
\hline & \multirow{2}{*}{$\frac{A}{m}$} & \multirow{2}{*}{$\frac{B}{C_{0}}$} & \multirow{2}{*}{$\frac{C}{T}$} & \multirow{2}{*}{$\frac{D}{t}$} & \multicolumn{3}{|c|}{$q_{t}(\mathrm{mg} / \mathrm{g})$} & \multicolumn{3}{|c|}{ Percentage removal $(\%)$} & \\
\hline & & & & & $R_{1}$ & $R_{2}$ & $R_{3}$ & $R_{1}$ & $R_{2}$ & $R_{3}$ & \\
\hline 1 & 0.5 & 300 & 20 & 60 & 29.16 & 29.05 & 29.21 & 97.20 & 96.82 & 97.37 & 29.29 \\
\hline 2 & 0.5 & 200 & 40 & 30 & 19.97 & 19.98 & 19.99 & 99.85 & 99.91 & 99.97 & 26.01 \\
\hline 3 & 0.75 & 100 & 40 & 60 & 6.66 & 6.66 & 6.66 & 99.95 & 99.94 & 99.96 & 16.47 \\
\hline 4 & 0.25 & 200 & 30 & 60 & 35.24 & 35.32 & 35.20 & 88.10 & 88.30 & 88.00 & 30.94 \\
\hline 5 & 0.75 & 200 & 20 & 90 & 13.33 & 13.33 & 13.33 & 99.95 & 99.94 & 99.95 & 22.49 \\
\hline 6 & 0.75 & 300 & 30 & 30 & 19.84 & 19.90 & 19.93 & 99.18 & 99.51 & 99.67 & 25.97 \\
\hline 7 & 0.25 & 300 & 40 & 90 & 57.81 & 56.92 & 57.33 & 96.35 & 94.86 & 95.56 & 35.17 \\
\hline 8 & 0.5 & 100 & 30 & 90 & 9.99 & 10.00 & 9.99 & 99.92 & 99.97 & 99.87 & 19.99 \\
\hline 9 & 0.25 & 100 & 20 & 30 & 18.35 & 17.63 & 18.84 & 91.75 & 88.15 & 94.22 & 25.23 \\
\hline
\end{tabular}

removal of ICD and MBD individually using AC derived from sawdust of Acacia Nilotica under aqueous conditions. The significant parameters affecting the adsorptive removal of dye, the range of values and their levels are shown in table 1. As shown in table 2, four parameters, each at three levels, were used in Taguchi's $L_{9}\left(3^{4}\right)$ OA. A set of 9 experiments were carried out in triplicate under the conditions given in table 3 . The experimental output for each run and $S / N$ calculated for bigger and better condition for ICD and MBD on ACSA are shown in tables 4 and 5, respectively. The $S / N$ ratio for bigger and better condition is considered because this ratio gives the strongest group of parametric conditions.

From tables 4 and 5, as well as in accordance with the parametric values set by Taguchi's $L_{9}\left(3^{4}\right) \mathrm{OA}$, it can be inferred that in case of adsorption of ICD onto ACSA (table 4$)$, the value of $S / N$ ratio for each parameter at levels 1-3 is maximum (i.e., 29.83) for run no.7. Similarly, the mean value of adsorption capacity for each parameter at levels $1-3$ is also found to be maximum (i.e., $31.01 \mathrm{mg} / \mathrm{g}$ ) though percentage removal is found to be decreased (i.e., $77.5 \%$ ). Likewise, in case of adsorption of MBD onto ACSA (table 5), the value of $S / N$ ratio for each parameter at levels
1-3 is also maximum (i.e., 35.17) for run no. 7. Similarly, the mean value of adsorption capacity for each parameter at levels $1-3$ is also found to be maximum (i.e., $57.35 \mathrm{mg} / \mathrm{g}$ ) though percentage removal is found to be decreased (i.e., $95.6 \%$ ). Thus it is observed that ICD and MBD adsorption is strongly dependent on the parametric conditions (i.e., adsorbent dose, initial concentration, temperature and time).

\subsection{Effect of process parameters}

Parameters like adsorbent dose $m(A)$, initial concentration $C_{0}(B)$, temperature $T(C)$ and contact time $t(D)$ at various levels significantly affect the response values $q_{t}$ (tables 4 and 5). For removal and optimization of both ICD and MBD using ACSA, the parameter $A$, i.e., adsorbent dose $(m)$, showed the highest influence at level 1, parameter $B$, i.e., initial dye concentration $\left(C_{0}\right)$, showed the highest influence at level 3 , parameter $C$, i.e., temperature $(T)$, showed the highest influence at level 3 and parameter $D$, i.e., contact time $(t)$, showed the highest influence at level 3 (figures 3 and 4, tables 6 and 7).

The variation between level 1 and level 2 (i.e., $L_{2}-L_{1}$ ) and level 2 and level 3 (i.e., $L_{3}-L_{2}$ ) shows the effect of one 


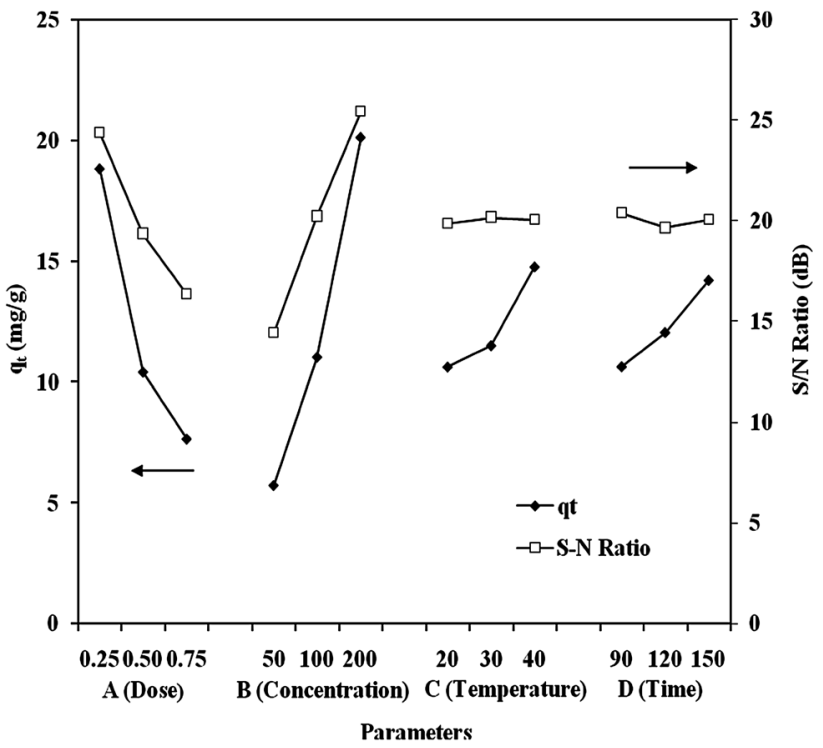

Figure 3. Effect of process parameters at sorption of ICD on ACSA surface at various levels.

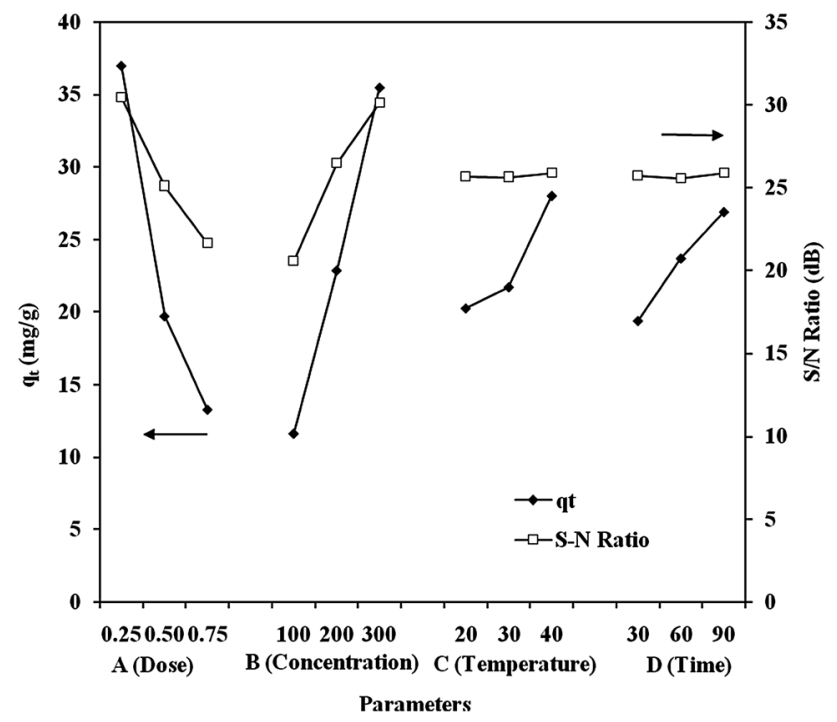

Figure 4. Effect of process parameters at sorption of MBD on ACSA surface at various levels.

over another. It also indicates that if variation between levels is higher, then the impact of levels is also higher. Tables 6 and 7 indicate that the parameter $B\left(C_{0}\right)$ showed the highest impact on $q_{t}$ values; $q_{t}$ value increases with increase in initial dye concentration $C_{0}$ because of more mass driving force and less resistance to the sorption uptake of ICD and MBD over ACSA surface [25, 30]. The percentage removal of ICD and MBD at optimum conditions is shown in tables 4 and 5 , respectively. The percentage removal was found to be $77.5 \%$ and $95.4 \%$ for ICD and MBD, respectively. Percentage removal of MBD was more as compared with ICD because the methylene blue dye has more attraction towards the negatively charged adsorbent surface $\left(\mathrm{pH}>\mathrm{pH}_{\mathrm{PZC}}\right)$ due to its cationic nature [25].

Figures 3 and 4 show the effect of process parameters on sorption of ICD and MBD on ACSA at various levels. For both ICD and MBD, it is observed that, with increase of parameter $A$, i.e., adsorbent dose $(m)$ from level 1 to level 3, there is decrease in adsorption capacity $\left(q_{t}\right)$. The decrease in adsorption capacity with increasing adsorbent dose is due to the exhaustion of adsorption sites and the accumulation of the particles due to closed contact at constant volume and also the reduction in adsorbate-adsorbent ratio with increasing adsorbent dose $(m)$ [31]. As the value of parameter $B$, i.e., initial dye concentration $\left(C_{0}\right)$, increases from level 1 to level 3 , the $q_{t}$ value also increases. The adsorption capacity $\left(q_{t}\right)$ increases with increasing initial dye concentration $\left(C_{0}\right)$ because of the decreased uptake between the aqueous phase and solid phase due to increased mass-transfer driving force for both ICD and MBD [5-8, 31]. It is also observed that adsorption of both ICD and MBD increases with the increase in parameter $C$, i.e., temperature $(T)$, from level 1 to level 3. This is because of the decrease in the viscosity of adsorbate solution (ICD and MBD), which increases the kinetic energy and mobility of the molecules. This ultimately results in an increase in the rate of diffusion. It also confirmed the endothermic nature of adsorption of both ICD and MBD by ACSA [25, 31]. With the increase of parameter $D$, i.e., contact time $(t)$, from level 1 to level $3, q_{t}$ also increases because of more vacant (free) sites available initially for sorption of both ICD and MBD over ACSA (figures 3 and 4). Similar type of results were also shown by Lataye et al $[6,7]$, in which the effects of different process parameters like concentration, dosage, $\mathrm{pH}$, time and temperature on simultaneous adsorption of Pyridine, $\alpha$-Picoline, $\gamma$-Picoline, 2-Picoline and 4-Picoline have been studied using Taguchi's optimization design on various adsorbents and batch studies.

Table 6. Average and main effects of $q_{t}$ values for sorption of ICD on ACSA: raw and $S / N$ data.

\begin{tabular}{|c|c|c|c|c|c|c|c|c|c|c|}
\hline \multirow[b]{2}{*}{ Parameters } & \multicolumn{3}{|c|}{ Raw data, average value } & \multicolumn{2}{|c|}{ Main effects (raw data) } & \multicolumn{3}{|c|}{$S / N$ data, average value } & \multicolumn{2}{|c|}{ Main effects ( $S / N$ data) } \\
\hline & $L_{1}$ & $L_{2}$ & $L_{3}$ & $L_{2}-L_{1}$ & $L_{3}-L_{2}$ & $L_{1}$ & $L_{2}$ & $L_{3}$ & $L_{2}-L_{1}$ & $L_{3}-L_{2}$ \\
\hline$A$ & 18.82 & 10.41 & 7.66 & -8.41 & -2.75 & 24.40 & 19.38 & 16.38 & -5.02 & -3.00 \\
\hline$B$ & 5.74 & 11.03 & 20.12 & 5.29 & 9.09 & 14.46 & 20.25 & 25.46 & 5.79 & 5.21 \\
\hline$C$ & 10.62 & 11.51 & 14.76 & 0.88 & 3.25 & 19.90 & 20.20 & 20.07 & 0.30 & -0.13 \\
\hline$D$ & 10.63 & 12.05 & 14.21 & 1.41 & 2.16 & 20.42 & 19.67 & 20.07 & -0.75 & 0.39 \\
\hline
\end{tabular}


Table 7. Average and main effects of $q_{t}$ values for sorption of MBD on ACSA: raw and $S / N$ data.

\begin{tabular}{|c|c|c|c|c|c|c|c|c|c|c|}
\hline \multirow[b]{2}{*}{ Parameters } & \multicolumn{3}{|c|}{ Raw data, average value } & \multicolumn{2}{|c|}{ Main effects (raw data) } & \multicolumn{3}{|c|}{$S / N$ data, average value } & \multicolumn{2}{|c|}{ Main effects ( $S / N$ data) } \\
\hline & $L_{1}$ & $L_{2}$ & $L_{3}$ & $L_{2}-L_{1}$ & $L_{3}-L_{2}$ & $L_{1}$ & $L_{2}$ & $L_{3}$ & $L_{2}-L_{1}$ & $L_{3}-L_{2}$ \\
\hline$A$ & 36.96 & 19.70 & 13.29 & -17.26 & -6.41 & 30.45 & 25.10 & 21.65 & -5.35 & -3.45 \\
\hline$B$ & 11.64 & 22.85 & 35.46 & 11.21 & 12.61 & 20.56 & 26.48 & 30.14 & 5.92 & 3.66 \\
\hline$C$ & 20.25 & 21.71 & 28.00 & 1.46 & 6.29 & 25.67 & 25.64 & 25.89 & -0.03 & 0.25 \\
\hline$D$ & 19.38 & 23.68 & 26.89 & 4.30 & 3.21 & 25.74 & 25.57 & 25.89 & -0.17 & 0.32 \\
\hline
\end{tabular}

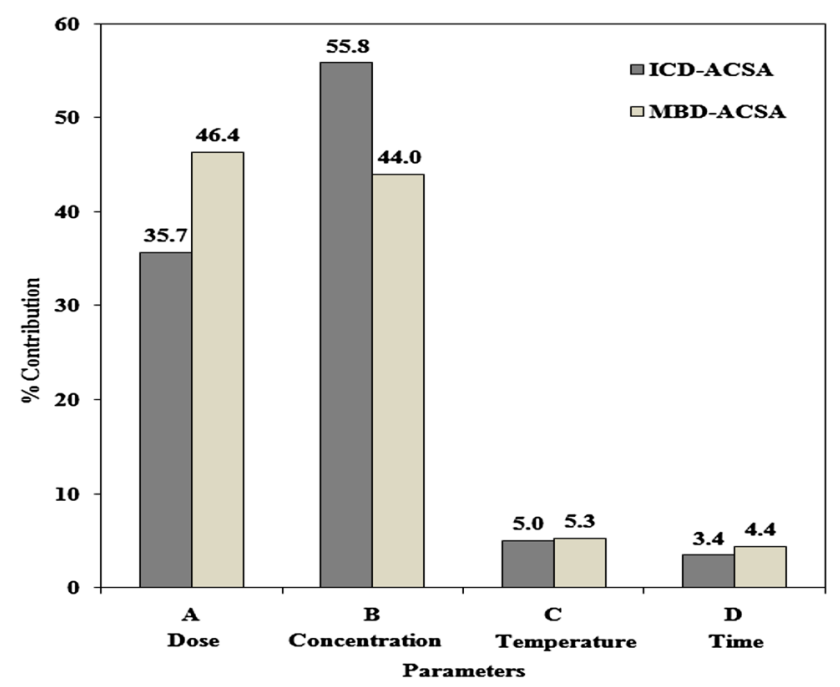

Figure 5. Individual percentage contribution of various parameters in sorption of ICD and MBD onto ACSA.
Figure 5 and tables 8 and 9 show the percentage contribution of various parameters in overall sorption of ICD and MBD on ACSA. From table 8 and figure 5, it can be observed that, for sorption of ICD, factor $B$, i.e., initial dye concentration $\left(C_{0}\right)$, shows the maximum percentage contribution of $55.8 \%$. This may be because the resistance to ICD uptake decreases as the mass-transfer driving force increases [25]. The second most influencing parameter is factor $A$, i.e., adsorbent dose $(m)$, with $35.7 \%$ contribution. After this, the parameter $C$, i.e., temperature $(T)$, shows $5 \%$ contribution while the last parameter $D$, i.e., time $(t)$, shows the least effect in sorption process with only $3.4 \%$ contribution.

Similarly, from table 9 and figure 5, it can be observed that for sorption of $\mathrm{MBD}$, factor $A$, i.e., adsorbent dose $(m)$, shows the maximum percentage contribution of $46.4 \%$. The second most influencing parameter is factor $B$, i.e., initial dye concentration $\left(C_{0}\right)$, with $44 \%$ contribution. After this, parameter $C$, i.e., temperature $(T)$, shows $5.3 \%$ contribution while the last parameter $D$, i.e., time $(t)$,

Table 8. ANOVA of ICD adsorption on ACSA.

\begin{tabular}{|c|c|c|c|c|c|c|c|c|c|c|c|}
\hline \multirow[b]{2}{*}{ Parameters } & \multicolumn{5}{|c|}{ ANOVA $q_{t}$} & \multirow[b]{2}{*}{$p$} & \multicolumn{5}{|c|}{ Pooled ANOVA $q_{t}$} \\
\hline & $S$ & $f$ & $V$ & $F$ & $\%$ & & $S$ & $f$ & $V$ & $F$ & $\%$ \\
\hline$A$ & 608.41 & 2 & 304.21 & 16653.40 & 35.70 & 0.00001 & 608.41 & 2 & 304.20 & 103.76 & 35.36 \\
\hline$B$ & 951.72 & 2 & 475.86 & 26050.37 & 55.84 & 0.00001 & 951.71 & 2 & 475.85 & 162.32 & 55.50 \\
\hline$C$ & 85.49 & 2 & 42.75 & 2340.14 & 5.02 & 0.00001 & 85.49 & 2 & 42.74 & 14.581 & 4.67 \\
\hline$D$ & 58.30 & 2 & 29.15 & 1595.88 & 3.42 & 0.00001 & 0 & 0 & 0 & 0 & 0 \\
\hline Error & 0.33 & 18 & 0.02 & 1 & 0.02 & & 58.63 & 20 & 2.93 & 1 & 4.47 \\
\hline Totals & 1704.26 & 26 & 851.98 & & 100 & & 1704.25 & 26 & 825.74 & & 100 \\
\hline
\end{tabular}

Table 9. ANOVA of MBD adsorption on ACSA.

\begin{tabular}{|c|c|c|c|c|c|c|c|c|c|c|c|}
\hline \multirow[b]{2}{*}{ Parameters } & \multicolumn{5}{|c|}{ ANOVA $q_{t}$} & \multirow[b]{2}{*}{$p$} & \multicolumn{5}{|c|}{ Pooled ANOVA $q_{t}$} \\
\hline & $S$ & $f$ & $V$ & $F$ & $\%$ & & $S$ & $f$ & $V$ & $F$ & $\%$ \\
\hline$A$ & 2697.01 & 2 & 1348.50 & 20768.41 & 46.38 & 0.00001 & 2697.00 & 2 & 1348.50 & 105.09 & 45.94 \\
\hline$B$ & 2555.68 & 2 & 1277.84 & 19680.08 & 43.95 & 0.00001 & 2555.67 & 2 & 1277.83 & 99.58 & 43.51 \\
\hline$C$ & 305.36 & 2 & 152.68 & 2351.46 & 5.25 & 0.00001 & 305.36 & 2 & 152.68 & 11.89 & 4.81 \\
\hline$D$ & 255.46 & 2 & 127.73 & 1967.20 & 4.39 & 0.00001 & 0 & 0 & 0 & 0 & 0 \\
\hline Error & 1.17 & 18 & 0.06 & 1 & 0.02 & & 256.63 & 20 & 12.83 & 1 & 5.74 \\
\hline Totals & 5814.68 & 26 & 2906.82 & & 100 & & 5814.68 & 26 & 2791.85 & & 100 \\
\hline
\end{tabular}


shows the least effect in sorption process with only $4.4 \%$ contribution. The percentage contribution of initial concentration in case of ICD is more, whereas in case of MBD adsorption the adsorbent dose contributed slightly higher than initial concentration, which may be due to the higher adsorbate-adsorbent ratio in case of MBD [25]. Similar results were are also shown by Singh et al [8], where the effect of various parameters on the adsorption of fluoride ions using Taguchi's optimization technique had been studied. The analysis showed that initial concentration is the most significant parameter followed by adsorbent dose in the adsorption. Likewise, in Lataye et al [7], the ANOVA showed that, in case of rice husk ash, the initial concentration of $\alpha$-Picoline is the most significant parameter with $27.6 \%$ and $27.8 \%$ contribution to the adsorption capacity for raw and $S / N$ ratio data, respectively. For granular AC, the adsorbent dose is the most significant parameter with $32.2 \%$ and $17.5 \%$ contribution to the adsorption capacity for raw and $S / N$ ratio data, respectively. The interactions between initial concentrations also contribute significantly to the overall sorption [7]. Similar types of analyses were also considered by Lataye et al [6] for the removal of Pyridine and its derivatives using bagasse fly ash as an adsorbent, the ANOVA showed that the adsorbent dose is the most significant parameter with $35.6 \%$ and $10.5 \%$ contribution to the $q_{t}$ and $S / N$ ratio data, respectively.

\subsection{Selection and estimation of optimum process parameters and response characteristics}

Statistics-based ANOVA technique is used to evaluate the percentage contribution $(\%)$ of each parameter in the process. It is used to classify and quantify the sources of different trial results from various trial runs (i.e., different parameters $A-D)$. It considers various factors such as $f(D O F), S, V, F, \%$, etc., and tests the differences in the average performance of various parameters [27, 28]. The significant characteristic of ANOVA (shown in tables 8 and 9) is that the total sum of the squares, i.e., ' $S$ ', is equal to the sum of the squares of the deviations of all the conditional parameters like $A-D$ and the error functions. The probability value $(p)$ helps in accounting the suitable and unsuitable significance level [32]. The result is significant at $p<0.05$. In the present study the $p$ values of all the parameters are less than $<0.05$, i.e. near zero, showing the significance of the parameters.

The DOF for error $\left(f_{e}\right)$ is the difference of total DOF $\left(f_{T}\right)$ and DOF for controlled factors $(A-D)$. It is calculated as follows:

$$
f_{e}=f_{T}-f_{A}-f_{B}-f_{C}-f_{D} .
$$

The sum of squares analysis $\left(S_{A}\right)$ for the factors is obtained as follows:

$$
S_{A}=A_{1}^{2} / N A_{1}+A_{2}^{2} / N A_{2}+A_{3}^{2} / N A_{3}-C F
$$

where $C F$ is correction factor, $N$ is number of experiments and $A_{1}-A_{3}$ are average effects. Variance is the ratio of sum of squares to DOF and is given as follows:

$$
V=S / f \text {. }
$$

Variance ratio is calculated as ratio of variance to variance for error $\left(V_{e}\right)$ and is stated as follows:

$$
F=V / V_{e}
$$

Pure sum of squares $\left(P S_{A}\right)$ is determined using the relation between total DOF and DOF for error and is calculated as follows:

$$
P S_{A}=S_{A}-\left(F V_{e}\right)
$$

Finally, percentage contribution (\%) for any factor is obtained as follows:

$$
\%=\left(P S_{A} / S_{t}\right) \times 100
$$

where $S_{t}$ is sum of square of all trial run results. All the values are shown in tables 8 and 9. To optimize the response value, i.e., $q_{t}$ for sorption of ICD and MBD by ACSA, the maximum values of $q_{t}$ at certain levels for a particular factor have to be selected [2]. From response curves of figures 3 and 4 and tables 8 and 9 it was observed that for both ICD and MBD adsorption on ACSA, first level of factor $A$ (adsorbent dose, $m$ ), third level of factor $B$ (initial concentration, $C_{0}$ ), third level of factor $C$ (temperature, $T$ ) and third level of factor $D$ (time, $t$ ) have higher values of $q_{t}$.

The average values of $q_{t}(\mathrm{mg} / \mathrm{g})$ for optimal level of parameters for ICD adsorption on ACSA (Eqs. (15)-(19)) are as given:

$$
\begin{aligned}
\bar{A}_{1} & =18.82, \bar{B}_{3}=20.12, \bar{C}_{3}=14.76 \text { and } \bar{D}_{3} \\
& =14.21(\text { from table } 6) .
\end{aligned}
$$

Grand total of all results $T=331.99$

$\mathrm{mg} / \mathrm{g}$ and total number of results $(N)=27$.

$$
\begin{gathered}
\text { Therefore } \bar{T}=T / N=12.29 . \\
\mu_{A C S A}=\bar{T}+\left(\bar{A}_{1}-\bar{T}\right)+\left(\bar{B}_{3}-\bar{T}\right)+\left(\bar{C}_{3}-\bar{T}\right) \\
+\left(\bar{D}_{3}-\bar{T}\right) \\
=31.02 \mathrm{mg} / \mathrm{g} .
\end{gathered}
$$

The $95 \%$ confidence interval for the mean of population and three confirmation experiments $\left(C I_{P O P}\right.$ and $\left.C I_{C E}\right)$ for ICD adsorption on ACSA (Eqs. (20) and (21)) are determined by replacing $N=$ total numbers of results $=9 \times 3=27$ [3], $f_{e}$ (DOF error) $=26-8=18, V_{e}$ (recalculated error variance after pooling ANOVA) $=2.932$ (from table 7 ) in (Eqs. (6)-(8)). 
Table 10. Predicted optimal $q_{t}$ values, confidence interval and result of confirmation experiment.

\begin{tabular}{|c|c|c|c|c|c|c|}
\hline Adsorbent & Adsorbent & $\begin{array}{l}\text { Optimal level } \\
\text { process } \\
\text { parameters }\end{array}$ & $\begin{array}{c}\text { Predicted } \\
\text { optimal value } \\
(\mathrm{mg} / \mathrm{g})\end{array}$ & $\begin{array}{c}\text { Confidence interval } \\
95 \%\end{array}$ & $\begin{array}{c}\text { Average } \\
\text { confirmation } \\
\text { capacity }(\mathrm{mg} / \mathrm{g})\end{array}$ & $\begin{array}{c}\text { Average of verification } \\
\text { experiment }(\mathrm{mg} / \mathrm{g})\end{array}$ \\
\hline ACSA & ICD & $\mathrm{A}_{1} \mathrm{~B}_{3} \mathrm{C}_{3} \mathrm{D}_{3}$ & 31.02 & $\begin{array}{c}C I_{P O P}: \\
28.94<\mu_{A C S A}<33.09 \\
C I_{C E}: \\
28.83<\mu_{A C S A}<32.20\end{array}$ & 31.01 & 30.76 \\
\hline ACSA & MBD & $\mathrm{A}_{1} \mathrm{~B}_{3} \mathrm{C}_{3} \mathrm{D}_{3}$ & 57.35 & $\begin{array}{c}C I_{P O P}: \\
53.01<\mu_{A C S A}<61.70 \\
C I_{C E}: \\
52.77<\mu_{A C S A}<61.93\end{array}$ & 57.36 & 57.35 \\
\hline
\end{tabular}

$$
\begin{aligned}
& n_{\text {eff }}= \\
& \frac{N}{1+[\text { total } D O F \text { associated in the estimate of the mean }]} \\
& =3 .
\end{aligned}
$$

$F 0.05(1,18)=4.4139$ (from standard $F$-distribution table).

Therefore

$$
\begin{gathered}
C I_{P O P}=\sqrt{\frac{F_{\alpha}\left(1, f_{e}\right) V_{e}}{n_{e f f}}}= \pm 2.077 \\
C I_{C E}=\sqrt{F_{\alpha}\left(1, f_{e}\right) V_{e}\left[\frac{1}{n_{e f f}}+\frac{1}{R}\right]}= \pm 2.189
\end{gathered}
$$

Similarly, the average values of $q_{t}(\mathrm{mg} / \mathrm{g})$ for optimal level of parameters for MBD adsorption on ACSA (Eq. 22 26) are as given:

$$
\begin{aligned}
\bar{A}_{1} & =36.96, \bar{B}_{3}=35.46, \bar{C}_{3}=28.00 \text { and } \bar{D}_{3} \\
& =26.89(\text { from table } 6) .
\end{aligned}
$$

Grand total of all results $T=629.62 \mathrm{mg} / \mathrm{g}$ and total number of results $(N)=27$.

Therefore $\bar{T}=T / N=23.32$,

$$
\begin{aligned}
\mu_{A C S A}= & \bar{T}+\left(\bar{A}_{1}-\bar{T}\right)+\left(\bar{B}_{3}-\bar{T}\right)+\left(\bar{C}_{3}-\bar{T}\right) \\
& +\left(\bar{D}_{3}-\bar{T}\right) \\
= & 57.35 \mathrm{mg} / \mathrm{g}
\end{aligned}
$$

The $95 \%$ confidence interval for the mean of population and three confirmation experiments $\left(C I_{P O P}\right.$ and $\left.C I_{C E}\right)$ for MBD adsorption on ACSA (Eqs. (27) and (28)) are calculated by substituting $N=$ total numbers of results $=9 \times 3=$ 27 [3], $f_{e}$ (DOF error) $=26-8=18, V_{e}$ (recalculated error variance after pooling ANOVA) $=12.832($ from table 7$)$ in (Eqs. (6)-(8)).

$$
\begin{aligned}
& n_{\text {eff }}= \\
& \frac{N}{1+[\text { total } D O F \text { associated in the estimate of the mean }]} \\
& =3 .
\end{aligned}
$$

$F 0.05(1,18)=4.4139$ (from standard $F$-distribution table).

Therefore

$$
\begin{gathered}
C I_{P O P}=\sqrt{\frac{F_{\alpha}\left(1, f_{e}\right) V_{e}}{n_{e f f}}}= \pm 4.345, \\
C I_{C E}=\sqrt{F_{\alpha}\left(1, f_{e}\right) V_{e}\left[\frac{1}{n_{e f f}}+\frac{1}{R}\right]}= \pm 4.580
\end{gathered}
$$

The predicted range, average confirmation capacity and average of verification experiment of $q_{t}$ for sorption of ICD and MBD on ACSA at $95 \% C I$ for $C I_{P O P}$ and $C I_{C E}$ are given in table 10 .

\subsection{Confirmation experiment}

In the present study, the combination for the optimized adsorption capacity for both the dyes was found to be $A_{1} B_{3} C_{3} D_{3}$, i.e., parameter $A$ at level 1 and parameters $B-$ $D$ at level 3. For both the dyes, the confirmation experiments were performed three times with the optimized combination of parameters and levels $\left(A_{1} B_{3} C_{3} D_{3}\right)$. From the confirmation experiment, the average of adsorption capacity was found to be $31.01 \mathrm{mg} / \mathrm{g}$ for ICD and $57.36 \mathrm{mg} / \mathrm{g}$ for MBD (shown in table 10). The verification experiments were performed again and the experimental values found were in the range of $95 \% C I$ for $C I_{C E}$ (table 10). Also, the probability values $(p)$ of all the parameters are found to be near zero, indicating the significance of all the parameters. The result shows the applicability of optimization strategy suggested by Taguchi's design. 


\section{Conclusions}

From the present study, it may be concluded that Taguchi's design of experimental methodology is one of the best methods to optimize various process parameters. Its application on adsorption and optimization of ICD and MBD by ACSA could be very sensible from resources, time and cost point of view. The 81 sets of experiments are reduced to nine sets only. The significant parameters for sorption such as adsorbent dose $(m)$, initial dye concentration $\left(C_{0}\right)$, temperature $(T)$ and contact time $(t)$ at three different levels are optimized in only nine sets of runs. For ICD, the parameter initial dye concentration $\left(C_{0}\right)$ was found to be the most significant parameter with $55.8 \%$ contribution followed by ACSA dose $(m)$ and temperature $(T)$ with $35.7 \%$ and $5 \%$ contribution in sorption process, respectively, whereas for MBD, the parameter ACSA dose $(m)$ was found to be the most significant parameter with $46.4 \%$ contribution followed by initial dye concentration $\left(C_{0}\right)$ and temperature (T) with $44 \%$ and $5.3 \%$ contribution in sorption process, respectively. The parameter contact time $(t)$ was found to be the least significant parameter with only $3.4 \%$ contribution for ICD and 4.4\% contribution for MBD in the overall sorption process. The optimized parameters at different levels for ICD were found to be $A_{1}, B_{3}, C_{3}$ and $D_{3}$, i.e., ACSA dose $(0.25 \mathrm{~g} / 50 \mathrm{~mL})$, ICD initial concentration $(200 \mathrm{mg} / \mathrm{L})$, temperature $\left(40^{\circ} \mathrm{C}\right)$ and contact time (150 min). Similarly, the optimized parameters at different levels for MBD were also found to be $A_{1}, B_{3}, C_{3}$ and $D_{3}$, i.e., ACSA dose $(0.25 \mathrm{~g} / 50 \mathrm{~mL})$, MBD initial concentration $(300 \mathrm{mg} / \mathrm{L})$, temperature $\left(40^{\circ} \mathrm{C}\right)$ and contact time $(90 \mathrm{~min})$. The percentage removal of ICD and MBD at optimum conditions was found to be $77.5 \%$ and $95.4 \%$, respectively. The predicted and average values (after confirmation) of total dye adsorbed on the adsorbent $\left(q_{t}\right)$ by Taguchi's optimization method for ICD adsorption onto ACSA were found to be 31.02 and $31.01 \mathrm{mg} / \mathrm{g}$, respectively, and 57.35 and $57.36 \mathrm{mg} / \mathrm{g}$, respectively, for MBD. Both the values for ICD and MBD lie in the range of $95 \% C I_{C E}$. It indicates the applicability of Taguchi's optimization method for ICD and MBD sorption onto ACSA.

$\begin{array}{ll}\text { List of symbols } \\ C_{0} \quad \text { the initial dye concentration }(\mathrm{mg} / \mathrm{L}) \\ C_{e} & \text { the equilibrium dye concentration }(\mathrm{mg} / \mathrm{L}) \\ C F & \text { correction factor } \\ C I & \text { confidence interval } \\ C I_{C E} & \begin{array}{l}\text { confidence interval for only a sample group or } \\ \text { group of experiments }\end{array} \\ C I_{P O P} & \begin{array}{l}\text { confidence interval for entire population } \\ F\end{array} \\ f & \text { variance ratio } \\ F_{\alpha} & \text { The degrees of freedom } F \text {-ratio at a confidence level of }(1-\alpha) \text { against } \\ & \text { DOF } 1 \text { and error DOF }\left(f_{e}\right) \\ f_{e} & \text { the degrees of freedom for error }\end{array}$

$\begin{array}{ll}f_{T} & \text { the difference of total DOF } \\ L & \text { number of levels for each parameter } \\ m & \text { the dose of the adsorbent }(\mathrm{g} / 50 \mathrm{~mL}) \\ q_{t} & \begin{array}{l}\text { the adsorption capacity or total dye adsorbed on } \\ \text { the adsorbent }(\mathrm{mg} / \mathrm{g})\end{array} \\ N & \text { number of possible number of experiments } \\ n_{e f f} & \text { efficiency of the adsorbent } \\ p & \text { the probability values } \\ P S_{A} & \text { the pure sum of squares } \\ \% & \text { the percentage contribution } \\ R & \text { the sample size for confirmation experiment } \\ S & \text { the sum of squares of the deviations } \\ S_{A} & \text { the sum of squares analysis } \\ S_{t} & \text { the sum of squares of all trial run results } \\ S / N & \text { signal to noise ratio } \\ \sigma^{2} & \text { variance of observations } \\ T & \text { absolute temperature }\left({ }^{\circ} \mathrm{C}\right) \\ t & \text { contact time of adsorption (min) } \\ \mu & \text { mean of response at the optimum condition } \\ \mu^{2} & \text { square of mean } \\ V & \text { variance } \\ V_{e} & \text { error variance from pooled ANOVA } \\ y_{i} & \text { observation of response variables for ' } n \text { ' trials }\end{array}$

\section{References}

[1] Wong Y, Szeto Y, Cheung W and McKay G 2004 Adsorption of acid dyes on chitosan-equilibrium isotherm analyses. Process Biochem. 39(6): 695-704

[2] Roy R 2001 Design of experiments using the Taguchi approach: 16 steps to product and process improvement. New York: John Wiley and Sons, pp. 110-136

[3] Taguchi G and $\mathrm{Wu} \mathrm{Y} 1979$ Introduction to the off-line quality control. Japan: Central Japan Quality Control Association Nagaya, pp. 36-97

[4] Roy R 1990 A primer on the Taguchi method, 2nd ed. Michigan: Society of Manufacturing Engineers-Van Nostrand Reinhold, pp. 83-88

[5] Srivastava V, Mall I and Mishra I 2007 Multicomponent adsorption study of metal ions onto bagasse fly ash using Taguchi's design of experimental methodology. Ind. Eng. Chem. Res. 46(17): 5697-5706

[6] Lataye D, Mishra I and Mall I 2008 Multicomponent sorptive removal of toxics-pyridine, 2-picoline and 4-picoline from aqueous solution by bagasse fly ash: optimization of process parameters. Ind. Eng. Chem. Res. 47(15): 5629-5635

[7] Lataye D, Mishra I and Mall I 2009 Multicomponent sorption of pyridine and its derivatives from aqueous solution on to rice husk ash and granular activated carbon. Pract. Period. Hazard. Toxic Radioact. Waste Manag. 13(4): 218-229

[8] Singh K, Lataye D and Wasewar K 2015 Adsorption of fluoride onto sugarcane bagasse (Saccharum Officinarum): an application of Taguchi's design experimental methodology. J. Indian Water Works Assoc. 47(1): 285-294

[9] Antony J 2001 Simultaneous optimization of multiple quality characteristics in manufacturing processes using Taguchi's 
quality loss function. Int. J. Adv. Manuf. Technol. 17(1): 134-138

[10] Yeniay O 2001 A comparison of the performances between a genetic algorithm and the Taguchi method over artificial problems. Turk. J. Eng. Environ. Sci. 25: 561-568

[11] Naitoh J, Brendan M and Fox M 1994 Severe hypotension, bronchospasm and urticaria from intravenous indigo carmine. Urology 44: 271-272

[12] Giri A, Banerjee T, Talukder G and Sharma A 1986 Effects of dyes (indigo carmine, metanil yellow, fast green FCF) and nitrite in vivo on bone marrow chromosomes of mice. Cancer Lett. 30: 315-320

[13] Yang J, Monk T and White P 1991 Acute hemodynamic effects of indigo carmine in the presence of compromised cardiac function. J. Clin. Anesth. 3: 320-323

[14] Parry R T 1993 Introduction in principles and applications of modified atmosphere packaging of foods, 1st ed. London: Blackie Academic Press (Chapman and Hall), pp. 1-18

[15] Tabbara M and Jama M 2012 A kinetic study of the discoloration of methylene blue dye by $\mathrm{Na}_{2} \mathrm{SO}_{3}$ comparison with $\mathrm{NaOH}$. J. Univ. Chem. Technol. Metall. 47(3): 275-282

[16] Ahmedna M, Johns M, Clarke S, Marshall W and Rao R 1997 Potential of agricultural by-product based activated carbons for use in raw sugar decolonization. J. Sci. Food Agric. 75(1): 117-124

[17] Lakshmi U, Srivastava V, Mall I and Lataye D 2009 Rice husk ash as an effective adsorbent: evaluation of adsorptive characteristics of indigo carmine. J. Environ. Manag. 90(2): 710-720

[18] Laszlo J 1996 Preparing an ion exchange resin from sugarcane bagasse to remove reactive dye from wastewater. Text. Chem. Color. 28(5): 13-17

[19] Namasivayam C and Kavitha D 2002 Removal of Congo Red from water by adsorption onto activated carbon prepared from coir pith, an agricultural solid waste. Dyes Pigments 54(1): 47-58

[20] BIS—Bureau of Indian Standards 1985 Indian Standard methods of test for soil: part 4-Grain size analysis, 2nd ed. IS 2720, New Delhi, India, 4: 6-8
[21] Ross P 1988 Taguchi techniques for quality engineering, 2nd ed. New York: McGraw Hill, pp. 50-59

[22] Ross P 1996 Taguchi techniques for quality engineering, 2nd ed. New York: McGraw Hill, pp. 102-179

[23] Byrne D and Taguchi S 1987 The Taguchi approach to parameter design. Qual. Prog. 20(12): 19-26

[24] Silva M, Carneiro L, Silva J, Oliveira I, Filho H and Almeida C 2014 An application of Taguchi method (Robust Design) to environmental engineering: evaluating advanced oxidation process in polyester-resin wastewater treatment. Am. J. Anal. Chem. 5: 828-837

[25] Gupta T and Lataye D 2017 Adsorption of indigo carmine dye onto acacia nilotica (babool) sawdust activated carbon. $J$. Hazard. Toxic Radioact. Waste 21(4): 04017013

[26] Barker T 1990 Engineering quality by design, 1st ed. New York: Marcel Dekker, pp. 21-35

[27] Yang W and Tarng Y 1998 Design optimization of cutting parameters for turning operations based on the Taguchi method. J. Mater. Process. Technol. 84: 122-129

[28] Singh H 2012 Taguchi optimization of process parameters: a review and case study. Int. J. Adv. Eng. Res. Stud. 1(3): $39-41$

[29] Muthukrishnana N and Davimb J 2009 Optimization of machining parameters of $\mathrm{Al} / \mathrm{SiC}-\mathrm{MMC}$ with ANOVA and ANN analysis. J. Mater. Process. Technol. 209: 225-232

[30] Chowdhary S, Mishra R, Saha P and Kshwaha P 2011 Adsorption thermodynamics, kinetics and isosteric heat of adsorption of malachite green onto chemically modified rice husk. Desalination 265: 159-168

[31] Lataye D, Mishra I and Mall I 2008 Pyridine sorption from aqueous solution by rice husk ash (RHA) and granular activated carbon (GAC): parametric, kinetic, equilibrium and thermodynamic aspects. J. Hazard. Mater. 154: $858-870$

[32] Kowalczyk M 2014 Application of Taguchi and ANOVA methods in selection of process parameters for surface roughness in precision turning of titanium. Adv. Manuf. Sci. Technol. 38(2): 21-35 